\title{
PHYSICAL AND BIOCHEMICAL FRUIT QUALITY ATTRIBUTES OF POMEGRANATES (Punica granatum L.) AS AFFECTED BY DIFFERENT GENOTYPES AND GROWING SYSTEMS
}

\author{
KARAAT, F. E. ${ }^{{ }^{*}}-$ KUTSAL, I. K. ${ }^{2}$ \\ ${ }^{I}$ Adiyaman University, Faculty of Agriculture, Department of Plant Protection, 02040 \\ Adlyaman, Turkey \\ ${ }^{2}$ Malatya Turgut Özal University, Faculty of Agriculture, Department of Horticulture, 44210 \\ Malatya, Turkey \\ ${ }^{*}$ Corresponding author \\ e-mail:fkaraat@adiyaman.edu.tr \\ (Received $6^{\text {th }}$ Jan 2021; accepted $14^{\text {th }}$ May 2021)
}

\begin{abstract}
Due to its unique taste, high nutritional value and the wide range of uses, pomegranate is an important and popular fruit species. Pomegranate trees are widely cultivated around the world and organic cultivation of the species is a common practice. The more the importance of healthy foods is understood, the more the interest in organic fruits increases. Consequently, there is a need for knowledge of how organic farming influences fruit properties on different genotypes. For that reason, this study was conducted to evaluate and compare the sensorial, physical, and biochemical fruit quality attributes of two pomegranate genotypes ('Hicaznar' cultivar and a local commonly grown genotype, called 'Local' in this study) were both grown organically and conventionally in Adiyaman province of Turkey. Antioxidant activity ranged from 16.49 (conventional 'Hicaznar') to 37.71 (organic 'Local') $\mathrm{mm}$ Trolox/L, and total sugar between 120.25 (organic 'Local') and 152.50 (conventional 'Hicaznar') $\mu \mathrm{g} / \mathrm{g}$. Significant correlations were detected among variables, such as antioxidant activity was found as highly correlated with aril weight and maturity index ( $r=0.87$ and $r=0.66$, respectively), and also with sugar profile but in a negative way. Results indicated the different influence of growing systems on the genotypes and also confirmed the improved health benefits and overall quality of organic crops.
\end{abstract}

Keywords: antioxidants, cultivation, comparison, HPLC, phenolics

\section{Introduction}

Pomegranate (Punica granatum L.), a member of Punica genus of the Punicaceae family, is one of the oldest known fruit species originated from South Caucasia, Iran, Afghanistan, South and West Asia, and Anatolia where various pomegranate accessions areas can be found in natural spreading areas (Holland et al., 2009). Its fruits are consumed fresh or as processed to juice, but also vinegar and tannic acid, pectin, citric acid, paint and ink raw materials, oil, animal feed and various medicine row materials obtained from different fruit parts (İkinci, 2007).

Recent studies revealed the health benefits of pomegranate fruits especially the rich polyphenol contents and high antioxidant activity which are important properties that reduce the risks of chronic diseases and the fruit is classified as functional food (ViudaMartos et al., 2010; Tapias et al., 2014). Related findings increased the demand for pomegranate fruits and the search for high polyphenolics and antioxidant content genotypes.

Pomegranate is cultivated around the world and Turkey is one of the leading pomegranate producing countries with an annual production of more than half a million tons (FAO, 2021). As one of the areas of origin, Turkey hosts numerous local 
pomegranate accessions having a wide diversity of various plant and fruit characteristics (Çalışkan et al., 2017). Even though pomegranate accessions from different part of Turkey have been evaluated by different previous studies (Caliskan and Bayazit, 2012; Şimşek and Gülsoy, 2017), the accessions in Adiyaman province, one of the most important pomegranate origin and producer province of Turkey, have not been evaluated. In the province, there are various pomegranate accessions and some of them are cultivated locally and become popular in regional markets. Besides, organic farming of pomegranate is so common that a significant proportion of the pomegranates produced in the province are from organically managed orchards.

The idea of sustainable agriculture is producing quality crops with high yields together with a minimum impact on the environment but conventional agriculture practices have posed significant ecological problems (Mäder et al., 2002). Due to the different benefits including human health, environment, and biodiversity, organic agriculture has been suggested as an alternative to conventional agriculture and today up to $8 \%$ of agricultural areas in some European countries are managed organically (Drinkwater et al., 1998; Renagold et al., 2001; Mäder et al., 2002; Bengtsson et al., 2005; Hole et al., 2005; Pretty et al., 2006; Wood et al., 2006). Besides, compared to conventional ones organic products are preferred at the market thanks to their safety from pesticides but also the assumption of better taste and higher nutrient content (Ekelund and Tjarnemo, 2004; Gąstoł et al., 2011). On the other hand, organic farming comes together with higher costs and lower yield disadvantages for the farmers (Guichard et al., 2001). For those reasons, higher prices are asked for organic crops and that fact is generally met with the negative reactions of the consumers.

There are a few previous studies compared fruit samples obtained from organic and conventionally grown pomegranate trees. Nuncio-Jáuregui et al. (2015) compared some antioxidant properties of fresh and commercial fruit juices obtained from organic and conventionally grown 'Mollar de Elche' pomegranate cultivar. Similarly, CanoLamadrid et al. (2016) assessed some phytochemical attributes of fruit juices they prepared from organic and conventional fruits of 'Mollar de Elche' cultivar. Ahmadi et al. (2016) analyzed some physical and chemical parameters on organic and conventional 'Rabbabe-Shiraz' cultivar. However, previous studies still lack in comparing the effects of conventional and organic growing systems on fruit quality aspects of different genotypes. In this study, final market quality, sugar profile and antioxidant properties of fruits of two pomegranate genotypes having different characteristics from organic and conventionally grown orchards were compared.

\section{Materials and Methods}

\section{Plant Materials and Experimental Design}

This study was conducted in Kahta district of Adiyaman province in Turkey in 2019. The climatic conditions were within the multi-year averages of the area during the study. Some meteorological records of the experimental area are presented in Table 1 (MGM, 2019).

The plant materials of the study were seven years old pomegranate trees from two nearby orchards that eliminate climatic differences between the orchards one of which was organic and the other was grown conventionally $\left(37^{\circ} 45^{\prime} 46^{\prime \prime} \mathrm{N}-38^{\circ} 39^{\prime} 20^{\prime \prime} \mathrm{E}\right)$. In both of the orchards 'Hicaznar' cultivar, one of the most commonly grown pomegranate cultivar in Turkey consumed both fresh and processed (Caliskan and Bayazit, 2012), 
and a local genotype ('Local'), commonly grown in Adiyaman province consumed fresh, were planted. Fruits of 'Hicaznar' cultivar and 'Local' genotype are presented in Figure 1. Cultivation practices including drip irrigation, fertigation, pest management, and soil cultivation were performed as required.

Table 1. Some meteorological records of the experimental area

\begin{tabular}{c|cc|cc|cc|cc|cc|cc}
\hline & \multicolumn{2}{|c|}{ May } & \multicolumn{2}{c|}{ June } & \multicolumn{2}{c|}{ July } & \multicolumn{2}{c|}{ August } & \multicolumn{2}{c|}{ September } & \multicolumn{2}{c}{ October } \\
& 2019 & MYA & 2019 & MYA & 2019 & MYA & 2019 & MYA & 2019 & MYA & 2019 & MYA \\
\hline MT $\left({ }^{\circ} \mathrm{C}\right)$ & 22.7 & 20.4 & 28.6 & 26.6 & 30.2 & 30.9 & 31.5 & 30.6 & 26.6 & 25.8 & 18.7 & 19.1 \\
MMT $\left({ }^{\circ} \mathrm{C}\right)$ & 28,6 & 26.6 & 34.7 & 33.2 & 36.5 & 37.8 & 37.8 & 37.6 & 32.6 & 33.0 & 23.9 & 25.5 \\
MNT $\left({ }^{\circ} \mathrm{C}\right)$ & 16.9 & 14.3 & 22.5 & 19.7 & 24.3 & 23.6 & 25.4 & 23.4 & 20.5 & 19.0 & 12.9 & 13.6 \\
MP $(\mathrm{mm})$ & 45.5 & 42.6 & 2.9 & 8.4 & 0.7 & 1.7 & 11.8 & 1.9 & 5.9 & 7.6 & 41.1 & 46.2 \\
\hline
\end{tabular}

MT: Mean Temperature, MMT: Maximum Mean Temperature, MNT: Minimum Mean Temperature, MP: Monthly Precipitation, MYA: Multi-Year-Average
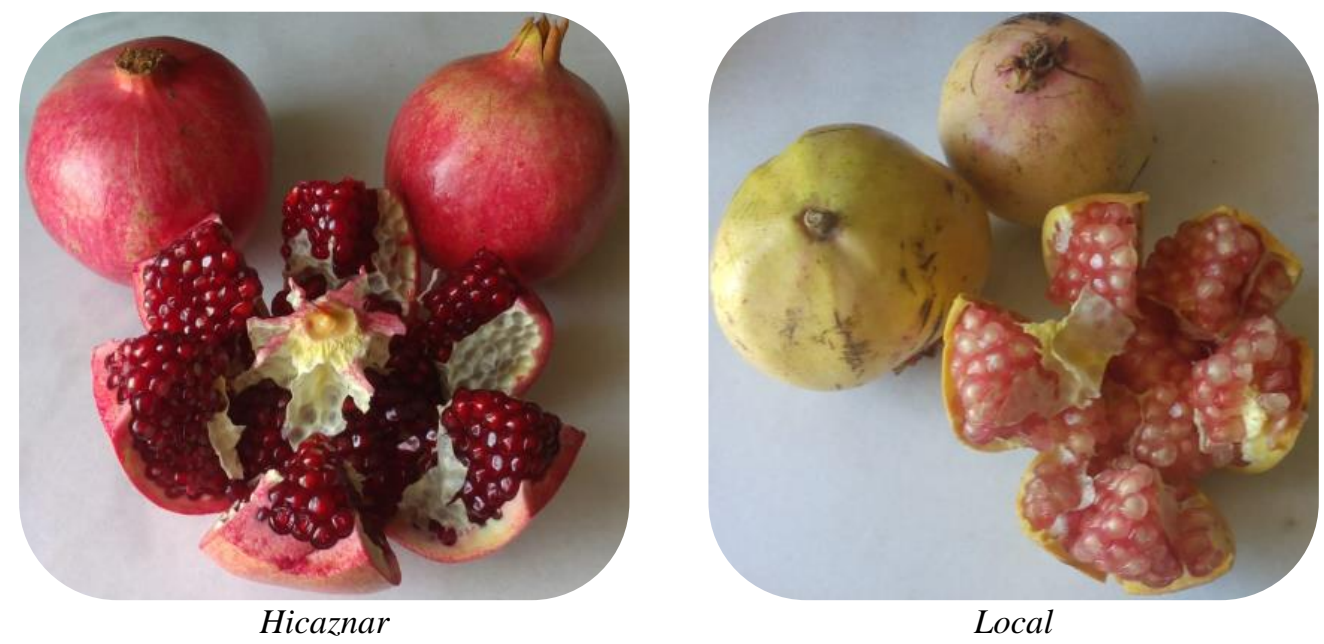

Figure 1. Fruit sample pictures of 'Hicaznar' and 'Local' pomegranate genotypes

The study was conducted according to randomized block design including the plantation and fruit sampling, and from each genotype 50 fruit samples were collected from 10 trees as required at the commercial maturity stage. Obtained fruit samples were subjected to sensorial, physical, and chemical evaluations.

\section{Sensorial Evaluations}

Sensory evaluations were performed by a panel to compare conventional and organic fruit samples of both genotypes. The panel consisted of four panelists two of which are trained professionals and the other two panelists were regular consumers. Panelists were asked to score sweetness, juiciness, aril color, and seed hardness from 1 to 7 according to the according to UPOV fruit descriptors (UPOV, 2012). Besides, appearance representing the market quality, a mixture of over color and fruit shape, was also scored by the panelists from 1 to 7 , where 0 was extremely low quality and 7 was extremely high quality. 


\section{Determination of Physical Fruit Properties}

As part of the physical evaluations; fruit weight, fruit length, fruit width, shape index, peel thickness, percent aril, and aril weight parameters were measured. Fruit weight was determined using precision scales and expressed in grams (g). Fruit length and fruit width were measured in millimeters $(\mathrm{mm})$ via digital calipers, and the shape index was calculated by dividing the fruit length by fruit width (UPOV, 2012). Peel thickness was also measured in $\mathrm{mm}$ via digital calipers. Percent aril represents the percentage of total aril weight of particular fruit weight, and the aril weight is the mean weight of arils ( $\mathrm{g}$ ) determined by weighting 50 arils using precision scales.

\section{Determination of Biochemical Fruit Properties}

In terms of biochemical characterization; total soluble solids, titration acidity, maturity index, total penolics content, antioxidant activity, and sugar profile (glucose, fructose, and total sugar content) were assessed. The total soluble solids content was measured by hand refractometer (Akyol 0-32\% Brix). Titration acidity (\%) was measured in terms of citric acid according to Altan (1992). Maturity index, an important trait for eating quality of fruits (Polat and Caliskan, 2008), was calculated by dividing total soluble solids content by titration acidity. Total phenolics content (mg GAE/100 $\mathrm{mL}$ ) was measured using Folin-Ciocalteu reagent according to the spectrophotometric (Shimadzu UV-1800) method described by Singleton and Rossi (1965). Antioxidant activity (mm Trolox/L) was measured using 2,2-Diphenyl-1-picrylhydrazyl (DPPH) radical according to the spectrophotometric method described by Blois (1958). Fructose $(\mu \mathrm{g} / \mathrm{g})$ and glucose $(\mu \mathrm{g} / \mathrm{g})$ contents were detected according to the HPLC method (Shimadzu Prominence LC-20A) suggested by Bartolomé et al. (1995), and total sugar contents were calculated by the addition of these sugar contents.

\section{Statistical Analysis}

Obtained data were subjected to statistical analyses performed using SPSS 23.0 for Windows software. Results were evaluated according to Duncan's test $(\mathrm{P} \leq 0.05)$. Correlations between traits were determined according to Pearson's correlation test.

\section{Results and Discussion}

Fruit samples from organic and conventionally grown pomegranate trees were evaluated in terms of sensorial, physical and chemical properties. Sensorial evaluation results were presented in Figure 2, and the results of the physical and chemical analyzes were shown in Table 2 and Table 3. Besides, correlation matrixes among assessed variables were given in Table 4.

\section{Results of Sensorial Evaluations}

From a general point of view, growing systems were similarly scored in sensorial evaluations but the genotypes were differently. Sweetness was higher in conventional samples of 'Local' genotype, but in organic samples in 'Hicaznar'. The sweetness of 'Local' was scored higher than 'Hicaznar'. Similarly, juiciness was higher in conventional samples of 'Local' and higher in organic samples of 'Hicaznar', but the level of juiciness was higher in 'Hicaznar'. Aril color was not changed between growing systems in 'Hicaznar' both of them scores as 'dark red'. On the other hand, the arils of 
the conventional 'Local' fruit samples were found more likely to be 'medium pink' in color, whereas 'light pink' in organic samples. Seeds of organic samples were found as slightly to be softer in organic samples in 'Local' but not in 'Hicaznar', and seeds of 'Hicaznar' were found harder than 'Local'. In terms of appearance, no difference between the growing systems was noticed in both of the genotypes, whereas 'Hicaznar' was found to have a better appearance.

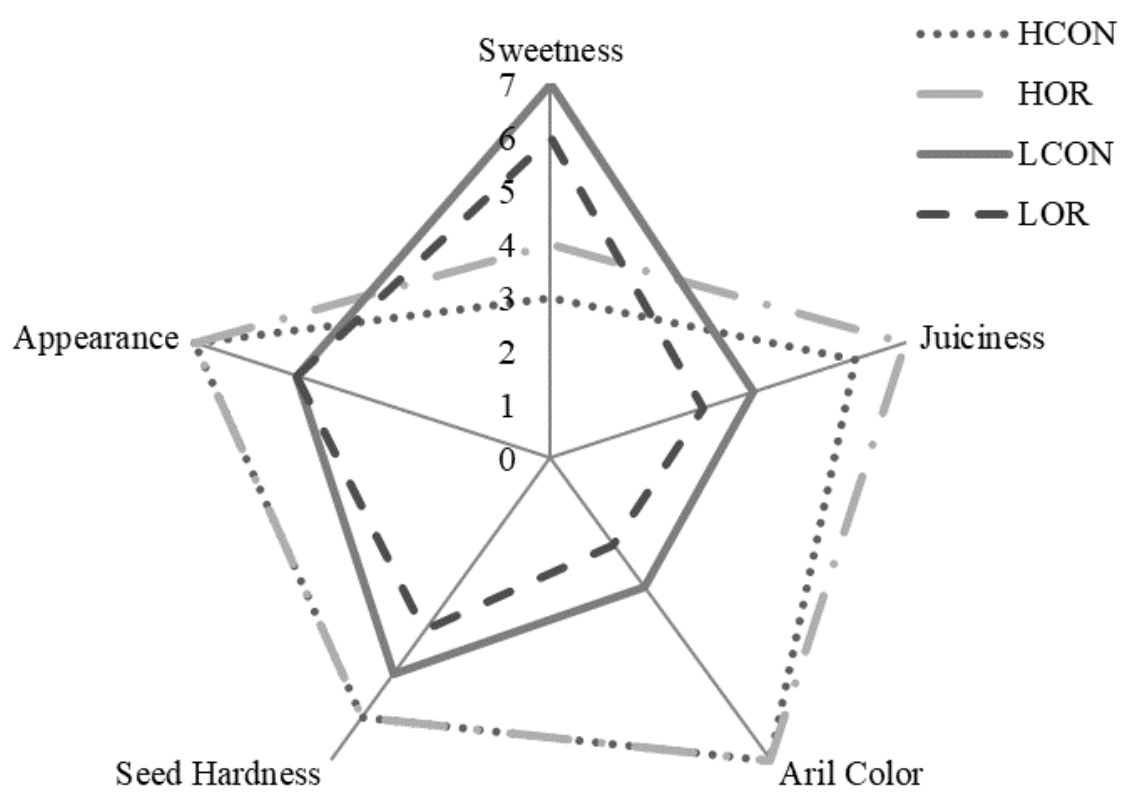

Figure 2. Sensory evaluation results of conventional and organic fruits of 'Hicaznar' and 'Local' pomegranate genotypes. HCON: Hicaznar Conventional, HOR: Hicaznar Organic, LCON: Local Conventional, LOR: Local Organic

Sensorial evaluations of the genotypes resulted as expected, but also for the growing systems as some differences were expected. The results of the sweetness were in accordance with the chemometric results. Similarly, Nuncio-Jáuregui et al. (2015) reported slightly higher sweetness for organic samples, whereas the authors reported slightly better color for conventional which was not found in both of the genotypes in this study. Ahmadi et al. (2016) reported no difference for seed hardness between organic and conventional fruits of 'Rabbabe-Shiraz' cultivar.

Table 2. Physical fruit assessment results of conventional and organic fruits of 'Hicaznar' and 'Local' pomegranate genotypes

\begin{tabular}{c|c|c|c|c}
\hline Characteristics & $\begin{array}{c}\text { Hicaznar } \\
\text { (Conventional) }\end{array}$ & $\begin{array}{c}\text { Hicazcar } \\
\text { (Organic) }\end{array}$ & $\begin{array}{c}\text { Local } \\
\text { (Conventional) }\end{array}$ & $\begin{array}{c}\text { Local } \\
\text { (Organic) }\end{array}$ \\
\hline Fruit Weight (g) & $462.31 \mathrm{~b}$ & $545.23 \mathrm{a}$ & $291.64 \mathrm{~d}$ & $359.14 \mathrm{c}$ \\
Fruit Length (mm) & $86.49 \mathrm{~b}$ & $92.99 \mathrm{a}$ & $73.31 \mathrm{c}$ & $85.79 \mathrm{~b}$ \\
Fruit Width (mm) & $102.86 \mathrm{a}$ & $108.66 \mathrm{a}$ & $90.08 \mathrm{~b}$ & $99.53 \mathrm{a}$ \\
Shape Index & $0.84 \mathrm{ab}$ & $0.86 \mathrm{a}$ & $0.81 \mathrm{~b}$ & $0.86 \mathrm{a}$ \\
Peel Thickness (mm) & $4.73 \mathrm{a}$ & $4.17 \mathrm{ab}$ & $3.10 \mathrm{~b}$ & $4.10 \mathrm{ab}$ \\
Percent Aril (\%) & $53.59 \mathrm{~b}$ & $49.17 \mathrm{~b}$ & $64.12 \mathrm{a}$ & $62.25 \mathrm{a}$ \\
Aril Weight (g) & $0.37 \mathrm{~b}$ & $0.40 \mathrm{~b}$ & $0.42 \mathrm{~b}$ & $0.58 \mathrm{a}$ \\
\hline
\end{tabular}

Different letters within the rows sign significant differences according to Duncan's Test at $\mathrm{P} \leq 0.05$ 
Table 3. Biochemical characterization of conventional and organic fruits of 'Hicaznar' and 'Local' pomegranate genotypes

\begin{tabular}{c|c|c|c|c}
\hline Characteristics & $\begin{array}{c}\text { Hicaznar } \\
\text { (Conventional) }\end{array}$ & $\begin{array}{c}\text { Hicazcar } \\
\text { (Organic) }\end{array}$ & $\begin{array}{c}\text { Local } \\
\text { (Conventional) }\end{array}$ & $\begin{array}{c}\text { Local } \\
\text { (Organic) }\end{array}$ \\
\hline TSS $(\%)$ & $16.20 \mathrm{ab}$ & $16.73 \mathrm{ab}$ & $16.93 \mathrm{a}$ & $15.07 \mathrm{~b}$ \\
TA $(\%)$ & $1.97 \mathrm{a}$ & $1.77 \mathrm{~b}$ & $1.30 \mathrm{c}$ & $1.24 \mathrm{c}$ \\
Maturity Index & $8.26 \mathrm{~b}$ & $9.61 \mathrm{~b}$ & $12.78 \mathrm{a}$ & $12.20 \mathrm{a}$ \\
TPC (mg GAE/100 mL) & 97.43 & 102.71 & 95.51 & 97.66 \\
AA (mm Trolox/L) & $16.49 \mathrm{c}$ & $20.58 \mathrm{bc}$ & $24.43 \mathrm{~b}$ & $37.71 \mathrm{a}$ \\
Glucose $(\mu \mathrm{g} / \mathrm{g})$ & $76.65 \mathrm{a}$ & $76.30 \mathrm{a}$ & $74.45 \mathrm{a}$ & $63.55 \mathrm{~b}$ \\
Fructose $(\mu \mathrm{g} / \mathrm{g})$ & $75.85 \mathrm{a}$ & $75.35 \mathrm{a}$ & $72.85 \mathrm{a}$ & $56.75 \mathrm{~b}$ \\
Total Sugar $(\mu \mathrm{g} / \mathrm{g})$ & $152.50 \mathrm{a}$ & $151.65 \mathrm{a}$ & $147.30 \mathrm{a}$ & $120.25 \mathrm{~b}$ \\
\hline
\end{tabular}

TSS: Total Soluble Solids; TA: Titration Acidity; TPC: Total Phenolic Content; AA: Antioxidant Activity. Different letters within the rows sign significant differences according to Duncan's Test at $\mathrm{P} \leq$ 0.05

Table 4. Correlations among the assessed variables of the pomegranate fruit samples

\begin{tabular}{|c|c|c|c|c|c|c|c|c|c|c|c|c|c|c|}
\hline & FL & FW & -SI & PT & $-\mathrm{PA}$ & $-\mathrm{AW}$ & -TSS & -TA & -MI & -ТPC & -AA & $-\mathrm{FC}$ & $-\mathrm{GC}$ & -TSC \\
\hline FWE & $0.82^{* *}$ & $0.76^{* *}$ & -0.51 & 0.38 & $-0.87^{* *}$ & -0.49 & -0.16 & $-0.71^{*}$ & $-0.74^{*}$ & -0.57 & -0.53 & -0.51 & -0.52 & -0.52 \\
\hline FL & & $0.95^{\text {** }}$ & -0.56 & $0.69^{*}$ & $-0.75^{* *}$ & -0.16 & -0.23 & -0.43 & -0.55 & -0.39 & -0.10 & -0.12 & -0.15 & -0.13 \\
\hline FWI & & & -0.28 & $0.73^{* *}$ & $-0.79^{* *}$ & -0.30 & -0.26 & -0.38 & -0.52 & -0.38 & -0.18 & -0.24 & -0.25 & -0.24 \\
\hline SI & & & & 0.21 & -0.21 & -0.45 & -0.03 & -0.26 & -0.27 & -0.20 & -0.20 & -0.42 & -0.34 & -0.39 \\
\hline PT & & & & & -0.43 & -0.17 & -0.39 & -0.36 & -0.52 & -0.02 & -0.08 & -0.09 & -0.09 & -0.09 \\
\hline PA & & & & & & $-0.60^{*}$ & -0.14 & -0.60 & $-0.64^{*}$ & -0.53 & $-0.58^{*}$ & -0.45 & -0.35 & -0.41 \\
\hline AW & & & & & & & -0.57 & -0.59 & -0.57 & -0.10 & $-0.87^{* *}$ & $-0.92^{* *}$ & $-0.85^{* *}$ & $-0.90^{* *}$ \\
\hline TSS & & & & & & & & -0.10 & -0.09 & -0.16 & $-0.61^{*}$ & -0.60 & -0.52 & -0.57 \\
\hline TA & & & & & & & & & $-0.97^{* *}$ & -0.38 & $-0.74^{*}$ & -0.60 & -0.56 & -0.59 \\
\hline MI & & & & & & & & & & -0.39 & $-0.66^{*}$ & -0.55 & -0.53 & -0.54 \\
\hline TPC & & & & & & & & & & & -0.17 & -0.24 & -0.22 & -0.23 \\
\hline AA & & & & & & & & & & & & $-0.89^{* *}$ & $-0.79^{*}$ & $-0.85^{* *}$ \\
\hline $\mathrm{FC}$ & & & & & & & & & & & & & $-0.97^{* *}$ & $-0.99^{* *}$ \\
\hline $\mathrm{GC}$ & & & & & & & & & & & & & & $-0.98^{* *}$ \\
\hline
\end{tabular}

*Correlations significant at $\mathrm{P} \leq 0.05 * *$ Correlations significant at $\mathrm{P} \leq 0.01$ according to Pearson's Test. FWE: Fruit Weight, FL: Fruit Length, FWI: Fruit Width, PT: Peel Thickness, PA: Percent Aril, AW: Aril Weight, TSS: Total Soluble Solids, TA: Titration Acidity, MI: Maturity Index, SI: Shape Index, TPC: Total Phenolics Content, AA: Antioxidant Activity, FC: Fructose, GC: Glucose, TSC: Total Sugar Content

\section{Results of Physical Fruit Properties}

Significant differences for all evaluated physical fruit attributes were obtained among genotypes except shape index. On the other hand, even though most of the physical parameters were significantly different between growing systems in 'Local' genotype, only fruit weight and fruit length were attributes that differed significantly between the growing systems in 'Hicaznar'. The highest fruit weight $(545.23 \mathrm{~g})$ was obtained in organic samples of 'Hicaznar', whereas conventional 'Local' gave the lowest fruit weight value (291.64 g). Similarly, organic 'Hicaznar' fruits presented the highest fruit length $(92.99 \mathrm{~mm})$, and the lowest value was obtained in conventional 'Local' (73.31 $\mathrm{mm}$ ). Also for fruit width, shape index, and peel thickness, the lowest values were measured in conventional 'Local' fruit samples $(90.08 \mathrm{~mm}, 0.81$, and $3.10 \mathrm{~mm}$, 
respectively), and no significant difference was determined among the rest of the genotypes. Percent aril was higher in 'Local' fruit samples (64.12 and $62.25 \%$ in conventional and organic samples, respectively) rather than 'Hicaznar' and no significant difference was observed between growing systems in both of the genotypes. The highest aril weight ( $0.52 \mathrm{~g})$ was detected in organic samples of 'Local' and the rest of the samples were in the same statistical group.

The obtained fruit physical evaluation results of 'Hicaznar' cultivar were within the range of values reported by previous studies (Gündoğdu et al., 2015). Besides, smaller fruit size values were also reported by some previous studies which could probably be caused by the ecological conditions and the crop load level (Polat et al., 2010). In terms of the difference between the growing systems, Ahmadi et al. (2016) also reported no difference between the growing systems in aril percent, but higher fruit weight in conventional fruit samples of 'Rabbabe-Shiraz. The difference could be caused by the different responses of the genotypes for growing conditions and also from the level of crop load as the nutrient availability for each fruit could be differed by the effects of these factors (Fattahi et al., 2020).

\section{Results of Biochemical Fruit Properties}

In terms of the biochemical characterization of the genotypes and growing systems, significant differences were detected except total phenolics content which was varied between 95.51 and $102.71 \mathrm{mg} \mathrm{GAE} / 100 \mathrm{~mL}$. The total soluble solids content was higher in conventional samples when compared to organic ones in 'Local' (16.93 and 15.07\%, respectively), whereas no significant differences were found in 'Hicaznar' samples and they were in the same group with conventional 'Local'. Titration acidity was higher in conventional samples of 'Hicaznar' $(1.97 \%)$ when compared to the organic samples and both of them were found to be higher than 'Local' as expected. However, there was no significant difference between organic and conventional samples of 'Local'. The maturity index did not differ between the growing systems in both of the genotypes but higher in 'Local' samples (12.78 and 12.20 in conventional and organic, respectively). The highest and the lowest antioxidant activity values were obtained from organic 'Local' and conventional 'Hicaznar' samples, 37.71 and $16.49 \mathrm{~mm}$ Trolox/L, respectively. Antioxidant activity was significantly higher in organic samples in 'Local', but also in 'Hicaznar' organic samples tend to be higher. In terms of sugar profile, no significant differences were found among 'Hicaznar' samples and conventional 'Local' which were higher than organic 'Local' given the lowest values for each sugar specification $(63.55,56.75$, and $120.25 \mu \mathrm{g} / \mathrm{g}$ for glucose, fructose, and total sugar, respectively).

Total soluble solids, titration acidity, and maturity index, parameters influencing the taste, were found in accordance with sensorial sweetness scores. Similar results of total soluble solids, acidity, and total phenolics for 'Hicaznar' were reported by previous studies (Polat et al., 2010; Caliskan and Bayazit, 2012; Horuz et al., 2012). Results reported by Ahmadi et al. (2016) confirmed the influence of growing systems on total soluble solids and maturity index as no significant differences were found between organic and conventional samples. The authors found no influence of growing systems also on titration acidity confirming the results obtained from 'Local' samples in this current study.

Majority of the previous studies confirmed no influence of organic and conventional growing systems on total phenolics content (Gastol et al., 2011; Cano-Lamadrid et al., 
2016; Ahmadi et al., 2016) together with the exceptions that Nuncio-Jáuregui et al. (2015) found higher total phenolics content in organic pomegranate. On the other hand, there were various results reported for antioxidant activity. Cano-Lamadrid et al. (2016) reported no influence of the growing systems, whereas Nuncio-Jáuregui et al. (2015) found lower, but Ahmadi et al. (2016) found higher antioxidant activity values in organic samples when compared to their conventional samples. As a basic principle of organic agriculture, it is aimed to balance natural resources in an optimum way, whereas there is no such concern in conventional agriculture. Because of this basic difference, fruits obtained from conventional farming are supposed to contain fewer amounts of secondary metabolites that inducing bioactive compounds and antioxidant activity (Dani et al., 2007; Roussos, 2011). On the other hand, nutrient availability, especially the nitrogen, influences the concentration of the secondary metabolites that point to be higher in conventional crops (Berry et al., 2002; de Oliveira et al., 2017). For those reasons, the contradictory results on antioxidant activity found in the comparison of organic and conventional fruits are probably be caused by the interactive changes of the relevant factors that can vary by the influence of many factors such as genotypic and environmental influences. Similar interactive influences would also be the reason for the differences in the sugar profile results obtained from different growing systems and the genotypes (Veberic et al., 2010).

\section{Correlations}

Correlation test results indicated positive high correlations among the fruit weight and fruit sizes as expected. Besides, fruit weight was also found as positively and highly correlated with titration acidity, and also with percent aril and maturity index but in a negative way. Fruit sizes were found as positively and highly correlated with peel thickness, and negatively with percent aril. Percent aril was also found as correlated with maturity index but positively, and also moderately correlated with antioxidant activity in a positive way. Significant, high and negative correlations were obtained for aril weight with antioxidant activity, fructose, glucose, and total sugar content. The total soluble solids content was found to be negatively correlating with antioxidant activity. Titration acidity was also found negatively high correlated with antioxidant activity but also with maturity index. A negative and high correlation was obtained between the maturity index and antioxidant activity. Antioxidant activity and sugar properties were found as negatively and highly correlated.

Together with some additional correlations obtained for the parameters assessed as part of this current study, Ahmadi et al. (2016) reported a negative moderate correlation between aril weight and antioxidant activity, and also between total soluble solids and antioxidant activity which were also found in this study but with a higher coefficient. The authors also reported a positive moderate correlation between antioxidant activity and total phenolics content which is opposite to this study. On the other hand, the results of Cano-Lamadrid et al. (2016) indicated the correlation between antioxidant activity and total phenolics content was not significant.

\section{Conclusions}

In this study, fresh fruit samples of a common cultivar and a local commonly grown genotype from organic and conventional agricultural practices were evaluated in terms of their sensorial, physical and biochemical quality attributes. The study provided 
beneficial information on how growing systems influence different genotypes in terms of the assessed characteristics. The obtained results indicated significant differences for most of the evaluated parameters among the genotypes and growing systems. The effects of the growing systems were found to be different in the genotypes for several fruit properties. Significant correlations were calculated among the physical and the biochemical parameters in both positive and negative. As a result of the study it was concluded that for most of the genotypes, organic pomegranates would be healthier especially because of the increased antioxidant activity and advantageous in terms of sensorial quality. It would be helpful for growers and also consumers if the findings of the current study would be confirmed by the future studies conducted in different ecological conditions and different genotypes including the same and also different fruit quality attributes.

\section{REFERENCES}

[1] Ahmadi, M., Ghasemnezhad, M., Meighani, H., Kavoosi, M. (2016): A comparison of conventional, integrated and organic management systems on the quality of pomegranate fruit cv. "Rabbab-e-Shiraz". - Journal of Horticultural Science 30: 447-456. (in Persian).

[2] Altan, A. (1992): Laboratuar tekniği (Laboratory technique). - Çukurova Üniversitesi, Adana.

[3] Bartolomé, A. P., Rupérez, P., Fúster, C. (1995): Pineapple fruit: morphological characteristics, chemical composition and sensory analysis of Red Spanish and Smooth Cayenne cultivars. - Food Chemistry 53(1): 75-79.

[4] Bengtsson, J., Ahnström, J., Weibull, A. C. (2005): The effects of organic agriculture on biodiversity and abundance: a meta-analysis. - Journal of Applied Ecology 42(2): 261269.

[5] Berry, P. M., Sylvester-Bradley, R., Philipps, L., Hatch, D. J., Cuttle, S. P., Rayns, F. W., Gosling, P. (2002): Is the productivity of organic farms restricted by the supply of available nitrogen? - Soil Use and Management 18: 248-255.

[6] Blois, M. S. (1958): Antioxidant determinations by the use of a stable free radical. Nature 181(4617): 1199-1200.

[7] Çalişkan, O., Bayazit, S. (2012): Phytochemical and antioxidant attributes of autochthonous Turkish pomegranates. - Scientia Horticulturae 147: 81-88.

[8] Çalişkan, O., Bayazit, S., Öktem, M., Ergül, A. (2017): Evaluation of the genetic diversity of pomegranate accessions from Turkey using new microsatellite markers. Turkish Journal of Agriculture and Forestry 41(2): 142-153.

[9] Cano-Lamadrid, M., Marhuenda-Egea, F. C., Hernández, F., Rosas-Burgos, E. C., Burgos-Hernández, A., Carbonell-Barrachina, A. A. (2016): Biological activity of conventional and organic pomegranate juices: Antioxidant and antimutagenic potential. Plant Foods for Human Nutrition 71(4): 375-380.

[10] Dani, C., Oliboni, L. S., Vanderlinde, R., Bonatto, D., Salvador, M., Henriques, J. A. P. (2007): Phenolic content and antioxidant activities of white and purple juices manufactured with organically-or conventionally-produced grapes. - Food and Chemical Toxicology 45(12): 2574-2580.

[11] de Oliveira, A. B., de Almeida Lopes, M. M., Moura, C. F. H., de Siqueira Oliveira, L., de Souza, K. O., Gomes Filho, E., Urban, L., de Miranda, M. R. A. (2017): Effects of organic vs. conventional farming systems on quality and antioxidant metabolism of passion fruit during maturation. - Scientia Horticulturae 222: 84-89.

[12] Drinkwater, L. E., Wagoner, P., Sarrantonio, M. (1998): Legume-based cropping systems have reduced carbon and nitrogen losses. - Nature 396(6708): 262-265. 
[13] Ekelund, L., Tjarnemo, H. (2004): Consumer preferences for organic vegetables - the case of Sweden. - Acta Horticulturae 655: 121-128.

[14] FAO (2021): Food and Agriculture Organization, Crop Statistics. - Available at: http://www.fao.org/faostat/en/\#data/QC (Available Date: 20.04.2021).

[15] Fattahi, E., Jafari, A., Fallahi, E. (2020): Hand thinning influence on fruit quality attributes of pomegranate (Punica granatum L. cv. 'Malase Yazdi'). - International Journal of Fruit Science 20(2): 377-386.

[16] Gąstoł, M., Świątkiewicz, I., Krośniak, M. (2011): Organic versus conventional - a comparative study on quality and nutritional value of fruit and vegetable juices. Biological Agriculture and Horticulture 27(3-4): 310-319.

[17] Guichard, S., Bertin, N., Leonardi, C., Gary, C. (2001): Tomato fruit quality in relation to water and carbon fluxes. - Agronomie 21: 385-392.

[18] Gündoğdu, M., Yılmaz, H., Canan, İ. (2015): Nar (Punica granatum L.) çeşit ve genotiplerin fizikokimyasal karakterizasyonu (Physicochemical characterization of pomegranate (Punica granatum 1.) varieties and genotypes). - International Journal of Agriculture and Wildlife Science 1(2): 57-65.

[19] Hole, D. G., Perkins, A. J., Wilson, J. D., Alexander, I. H., Grice, P. V., Evans, A. D. (2005): Does organic farming benefit biodiversity? - Biological Conservation 122(1): 113-130.

[20] Holland, D., Hatib, K., Bar-Ya'akov, I. (2009): Pomegranate: botany, horticulture, breeding. - Horticultural Reviews 35(2): 127-191.

[21] Horuz, E., Altan, A., Maskan, M. (2012): Spray drying and process optimization of unclarified pomegranate (Punica granatum) juice. - Drying Technology 30(7): 787-798.

[22] İkinci, A. (2007): Nar yetiştiriciliği. - Tarım Türk Dergisi 7: 12-16.

[23] Mäder, P., Fliessbach, A., Dubois, D., Gunst, L., Fried, P., Niggli, U. (2002): Soil fertility and biodiversity in organic farming. - Science 296(5573): 1694-1697.

[24] MGM. (2019): Resmi İstatistikler. - T.C. Tarım ve Orman Bakanlığı, Meteoroloji Genel Müdürlüğü (Cities \& Holiday Resorts, Turkish State Meteorological Service).

[25] Nuncio-Jáuregui, N., Cano-Lamadrid, M., Hernández, F., Carbonell-Barrachina, Á. A., Calín-Sánchez, Á. (2015): Comparison of fresh and commercial pomegranate juices from Mollar de Elche cultivar grown under conventional or organic farming practices. Beverages 1(2): 34-44.

[26] Polat, A. A., Caliskan, O. (2008): Fruit characteristics of table fig (Ficus carica) cultivars in subtropical climate conditions of the Mediterranean region. - New Zealand Journal of Crop and Horticultural Science 36(2): 107-115.

[27] Polat, A. A., Caliskan, O., Kamiloglu, O. (2010): Determination of pomological characteristics of some pomegranate cultivars in Dörtyol (Turkey) conditions. - Acta Horticulturae 940: 401-405.

[28] Pretty, J. N., Noble, A. D., Bossio, D., Dixon, J., Hine, R. E., Penning de Vries, F. W., Morison, J. I. (2006): Resource-conserving agriculture increases yields in developing countries. - Environmental Science \& Technology 40: 1114-1119.

[29] Reganold, J. P., Glover, J. D., Andrews, P. K., Hinman, H. R. (2001): Sustainability of three apple production systems. - Nature 410(6831): 926-930.

[30] Roussos, P. A. (2011): Phytochemicals and antioxidant capacity of orange (Citrus sinensis (1.) Osbeck cv. Salustiana) juice produced under organic and integrated farming system in Greece. - Scientia Horticulturae 129: 253-258.

[31] Şimsek, M., Gülsoy, E. (2017): A Research on pomegranate (Punica granatum L.) production potantial of Southeastern Anatolia Region. - Iğdır University Journal of the Institue of Science and Technology 7(2): 31-41.

[32] Singleton, V. L., Rossi, J. A. (1965): Colorimetry of total phenolics with phosphomolybdic-phosphotungstic acid reagents. - American Journal of Enology and Viticulture 16(3): 144-158. 
[33] Tapias, V., Cannon, J. R., Greenamyre, J. T. (2014): Pomegranate juice exacerbates oxidative stress and nigrostriatal degeneration in Parkinson's disease. - Neurobiology of Aging 35(5): 1162-1176.

[34] UPOV. (2012): Pomegranate. Guidelines for the conduct of tests for distinctness, uniformity and stability. - International union for the protection of new varieties of plants, Geneva. https://www.upov.int/edocs/mdocs/upov/en/twf_43/tg_pgran.pdf Available Date: 12.11.2020

[35] Veberic, R., Jurhar, J., Mikulic-Petkovsek, M., Stampar, F., Schmitzer, V. (2010): Comparative study of primary and secondary metabolites in 11 cultivars of persimmon fruit (Diospyros kaki L.). - Food Chemistry 119(2): 477-483.

[36] Viuda-Martos, M., Fernández-López, J., Pérez-Álvarez, J. A. (2010): Pomegranate and its many functional components as related to human health: a review. - Comprehensive Reviews in Food Science and Food Safety 9(6): 635-654.

[37] Wood, R., Lenzen, M., Dey, C., Lundie, S. (2006): A comparative study of some environmental impacts of conventional and organic farming in Australia. - Agricultural Systems 89(2-3): 324-348. 